\title{
Evaluation of Effectiveness and Safety of an ICU Insulin Infusion Protocol
}

\author{
Queenie Ngalob, ${ }^{1}$ Cecilia Jimeno, ${ }^{1,2}$ Iris Thiele Isip-Tan ${ }^{1,3}$ \\ ${ }^{1}$ Section of Endocrinology, Diabetes and Metabolism, Department of Medicine, University of the Philippines-Philippine General Hospital Manila \\ ${ }^{2}$ Department of Pharmacology, College of Medicine, University of the Philippines Manila \\ ${ }^{3}$ Medical Informatics Unit, College of Medicine, University of the Philippines Manila
}

\begin{abstract}
Objective. To evaluate the efficacy, safety, and clinical outcomes of, and protocol deviations with the use of the Modified Yale Insulin Infusion Protocol (IIP) compared to usual/standard care in the local setting.

Methods. Chart review of patients admitted in two ICUs over a 2-year period was done. Patients eligible for intensive glycemic control were identified. Efficacy, safety and clinical outcomes were compared between the Modified Yale IIP and usual/standard care. Charts managed with the IIP were appraised for protocol deviations.

Results. Eighty-one patients met the inclusion criteria and $34.6 \%$ used the IIP. The IIP group achieved a lower mean blood glucose ( 185.1 vs $212.1 \mathrm{mg} / \mathrm{dl}, \mathrm{p}<0.05)$. They reached normoglycemia (5 vs 12 hours, $\mathrm{p}<0.05$ ) and target range of $140-180 \mathrm{mg} / \mathrm{dl}(8.3$ vs 18.3 hours, $\mathrm{p}<0.05$ ) earlier. Hypoglycemia was rare (median $0 \%$ ) in both groups. No difference in mortality or morbidity was seen. Hospital (13.9 vs 8.1 days, $p<0.05)$ and ICU stay $(5.5$ vs 3.0 days, $p<0.05)$ were longer in the IIP group. A mean of 11 deviations per patient occurred, the majority of which were errors on insulin dose administered $(66.6 \%)$.
\end{abstract}

Conclusion. The Modified Yale IIP is efficaceous, safe and yielded better glycemic profiles than usual care. Majority of protocol deviations were on the insulin dose administered.

Key words: insulin infusion protocol, hyperglycemia, intensive care unit, Filipino

\section{INTRODUCTION}

Hyperglycemia is common among the critically ill. There is clear evidence that hyperglycemia is correlated with poor clinical outcomes and glycemic control confers better prognosis. ${ }^{1-8}$ The recommended strategy for glycemic control among the critically-ill is intravenous insulin adjusted based on a standardized protocol. The American Diabetes Association (ADA) recommends that insulin infusion protocols (IIP) be standardized in an institution. Its success is dependent on its adaptation to the hospital, adequate support from key local leaders, acceptance of the implementing staff and validation of the protocol. ${ }^{9}$

Numerous protocols in the medical, surgical and mixed ICUs have been published which showed efficacy and safety. One example is the Yale IIP which sets the glycemic target at $100-139 \mathrm{mg} / \mathrm{dl}$. This protocol was used in a purely medical ICU. It demonstrated efficacy with $52 \%$ of blood glucoses (BG) within target and $66 \%$ of BGs within the clinically desirable range of $80-139 \mathrm{mg} / \mathrm{dl}$. It is also safe, with a hypoglycemia rate of $0.3 \%$. Nursing staff perception was favorable. More than $70 \%$ of nurses

e-ISSN 2308-118x

Printed in the Philippines

Copyright $($ C 2014 by the JAFES

Received March 19, 2014. Accepted April 30, 2014. assessed the protocol as easy to use, effective and an improvement in the management of the critically ill. ${ }^{10}$

Efficacy, i.e., the ability of an IIP to achieve target glucose levels, and safety of an IIP are dependent on several factors. One is the intrinsic nature of the IIP which includes the way insulin drip rates are adjusted based on glucose changes. Another is how efficiently the protocol is implemented which depends on the skill of implementing staff, availability of resources and occurrence of protocol deviations.

In 2009, Josol, et al., modified the Yale IIP to target the new BG recommendations and adapt it to our hospital setting. The target BG was modified to $140-180 \mathrm{mg} / \mathrm{dl}$ to comply with the latest recommended glycemic targets for the critically-ill by the ADA. ${ }^{9}$ During its initial observation, use of the protocol resulted in earlier time to achieve target BG range. More BG measurements were within acceptable levels compared with other methods of glucose control. Less hypoglycemic events were observed with the use of the IIP. ${ }^{11}$

Corresponding author: Queenie G. Ngalob, MD

Section of Endocrinology, Diabetes and Metabolism

University of the Philippines-Philippine General Hospital

Taft Avenue Ermita

1000 Manila, Philippines

Telephone number : 554-8400 local 3230

E-mail:queenngalob@gmail.com 
Since 2009, the Modified Yale IIP has been used in the medical and central ICUs of our hospital at the discretion of attending physicians. Two years after its conception, we aim to evaluate the effectiveness and usability of the Modified Yale IIP in our setting and compare it with usual care.

\section{OBJECTIVES}

The objective of our study is to evaluate the effectiveness of the Modified Yale IIP and compare it to usual/standard care in our setting. Specifically, we aim to evaluate the following: efficacy outcomes (mean BG achieved, mean/median BG achieved once normoglycemic, mean/median time in hours to normoglycemic and target ranges, and mean percentage of total BG in normoglycemia, target and off-target ranges), safety outcomes (median percentage of BG in hypoglycemia and severe hypoglycemia), and clinical outcomes (all-cause mortality, cardiovascular mortality, morbidity, and duration of ICU and hospital stay). We also aim to evaluate the frequency and types of protocol deviations committed in the performance of the IIP.

\section{METHODOLOGY}

\section{Study Setting}

The study was conducted in the Medical (MICU) and Central ICUs (CENICU) of the Philippine General Hospital. Our institution is a tertiary university and general hospital which caters to patients from the capital city and provinces nationwide. The MICU is a 12-bed capacity facility which serves purely medical charity/ service patients. The nurse-patient ratio is 1:3-4. There are approximately 400 admissions in the MICU annually. Most common reasons for admission are myocardial infarction, respiratory failure and sepsis. ${ }^{12}$

The CENICU is a 12-bed capacity facility with 10 beds allotted for self-pay patients and 2 beds for charity/service patients. The nurse-patient ratio is 1:2-3 . There are also approximately 400 admissions in the CENICU annually. Cases are mixed medical \& surgical. The most common reasons for admission are respiratory failure and postoperative care for neurosurgical and cardiac surgery cases. ${ }^{13}$

In these ICUs, glycemic management is not standardized. Strategies for glycemic control are at the discretion of the attending physicians.

\section{Study Population}

All charts of patients admitted at the MICU and CENICU in the period of January 2010 to December 2011 were ordered for retrieval. Patients eligible for intensive glycemic control via an intravenous IIP were identified. Indications included (1) BG > $180 \mathrm{mg} / \mathrm{dl}$ on two consecutive determinations, (2) on nil per os or parenteral nutrition and (3) any of the following: critical care illness, hemodynamic instability, perioperative care, type 1 diabetes, and high dose steroids. Patients with diabetic ketoacidosis or hyperosmolar hyperglycemic state were excluded. Method of glycemic control was identified by review of doctors' orders. Patients who were managed suboptimally (e.g., went home against advice, advanced directives of "Do not Resuscitate" (DNR), refused interventions) were excluded from the control group and in the analysis of clinical outcomes for the Modified Yale Group.

\section{The Modified Yale Insulin Infusion Protocol}

The Yale III was created by Goldberg, et al., for the Yale University School of Medicine in 2004. ${ }^{10}$ It was originally designed to target BG of $100-139 \mathrm{mg} / \mathrm{dl}$. This protocol was chosen by Josol et al., because of its demonstrated efficacy, safety, ease of use and it was tested in a similar population to our ICU. ${ }^{11}$

Modifications of the Yale IIP including changing the target to $140-180 \mathrm{mg} / \mathrm{dl}$. The threshold for hypoglycemia correction was also revised. Insulin infusion is withheld once BG approaches $<100 \mathrm{mg} / \mathrm{dl}$ in contrast to the original Yale IIP where the threshold is at $\leq 74 \mathrm{mg} / \mathrm{d}$. These modifications were done to comply with latest recommended glycemic targets for the critically ill by the ADA and to minimize the risk for hypoglycemia. ${ }^{9}$

The Modified Yale IIP was introduced in our institution in 2009. It was discussed in several Department of Medicine conferences with consultants and house staff but there was no formal training. The IIP was taught to ICU nurses by an Endocrine consultant in several training sessions. Presently, it is not part of the standard ICU care for diabetics and is being used at the discretion of physicians.

\section{Study Design}

The study is a retrospective cohort. Chart review of the specified study population was done. Method of glycemic control was extracted via review of doctors orders on charts by the primary investigator. Charts with explicit written orders to start the Modified Yale Protocol were identified. The control group was composed of patient charts meeting the inclusion criteria but with explicit orders other than the Modified Yale protocol which included sliding scale insulin, subcutaneous insulin, nonstandardized intravenous insulin infusions among others.

Demographic and clinical data of patients were extracted from charts. Glucose measurements were extracted from standard vital monitoring sheets and doctors' and nurses' notes. These forms were similar regardless of method of glycemic control. Blood glucose in the first 72 hours on intensive glucose control were extracted to determine the efficacy and safety outcomes. Clinical outcomes were 
identified. All data were entered into a data collection form.

Outcomes were compared between the two groups. Type and frequency of protocol deviations were identified in charts which employed the Modified Yale IIP. In the IIP group, a subset analysis of all outcomes was done among patients with at most $50 \%$ protocol deviations which is the threshold set by the investigators as an acceptable number of deviations.

Missing chart entries on BG readings were interpreted as failure to take BG levels at the assigned time and considered protocol deviations. Charts missing entire glucose monitoring sheets or pages with the initial orders of glycemic management strategies were excluded from the analysis.

\section{Outcome Measures}

Outcomes were categorized into efficacy, safety and clinical events. Efficacy outcomes included the following: mean BG achieved, median BG achieved once normoglycemic (BG 70-180 mg/dl), mean/median time in hours to normoglycemia and target range $(140-180 \mathrm{mg} / \mathrm{dl})$, and mean percentage of total measurements in normoglycemia, target and off-target ranges (BG <70, >180 $\mathrm{mg} / \mathrm{dl})$. Safety outcomes included median percentage of BG in hypoglycemia and severe hypoglycemia. Hypoglycemia was defined as recorded BG measurements less than $70 \mathrm{mg} / \mathrm{dl}$ while severe hypoglycemia was defined as recorded BG measurements less than $40 \mathrm{mg} / \mathrm{dl}$.

Clinical outcomes included all-cause mortality, cardiovascular mortality (acute coronary syndrome, cerebrovascular accident, arrhythmia), morbidity in the ICU (new cardiovascular event; need for initiation of mechanical ventilation; need for initiation, reinitiation or addition of vasopressors; new infection; new renal dysfunction defined as initial serum creatinine $1.5 \mathrm{mg} / \mathrm{dl}$ or lower which increased to above $2.5 \mathrm{mg} / \mathrm{dl}$ or increase by at least two-fold from baseline; need for transfusion of packed RBC, excluding patients admitted for gastrointestinal bleeding), duration of ICU and hospital stay.

Protocol deviations were classified into three: timing of CBG monitoring (obtained \pm 15 minutes of specified time), insulin dose administered and errors on hypoglycemia correction (failure to stop the drip, give D50 or restart insulin drip rate at proper dose).

\section{Statistical Analysis}

To achieve $95 \%$ confidence and $80 \%$ power in detecting a significant difference between two independent means assuming $73.84 \% \pm 17.68 \%$ is the mean percentage of BG within normoglycemic range in the IIP group and 51.74\% $\pm 25.03 \%$ for the control group based on the study of Josol et al.,11 it was estimated that a minimum sample size of 17 cases were necessary in each group.

Baseline characteristics were summarized using frequencies and percentages for categorical variables and mean/median and standard deviation for continuous variables. Chi-square test for categorical variables and $\mathrm{T}$ test or Mann-Whitney Ranksum test for continuous variables were used to analyze baseline characteristics and BG measurements for efficacy and safety outcomes. Clinical events outcomes were compared using Chi-square test for mortality rate and T-test or Mann-Whitney Ranksum test for length of hospital stay and ICU stay. All statistical tests were considered significant if $p$-value is less than $5 \%$.

\section{Ethical Considerations}

The study protocol was reviewed and approved by the Technical Review Board (TRB) of the Department of Medicine and the UP Manila Research Ethics Board (UPMREB).

\section{RESULTS}

A total of 81 patients among the charts retrieved met the inclusion criteria. Twenty eight patients (34.6\%) were managed using the Modified Yale IIP. Figure 1 shows the composition of the study cohort.

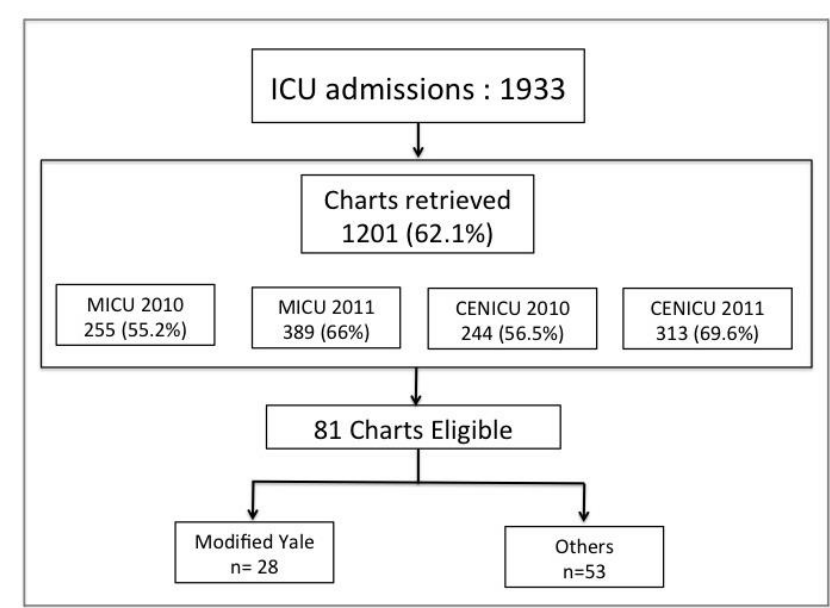

Figure 1. Composition of the Study Cohort

For the control group, $73.6 \%$ of patients were managed using sliding scale subcutaneous insulin. In 6 charts $(11.3 \%)$, intravenous insulin adjusted via a nonstandardized protocol was used. A combination of intravenous and intermittent subcutaneous insulin was also used in 5 charts $(9.4 \%)$. Majority $(65.3 \%)$ of BG determination and insulin interventions were done every 4 hours.

Baseline characteristics of the two groups were comparable, except for a greater proportion of diabetes 
and sepsis in the IIP group. Despite the disparity, initial blood glucose measurements were similar. APACHE II scores were 24 and 21 in the IIP and control groups respectively and were statistically similar. Both levels denote severe illness with a risk for mortality of at least $54.4 \%{ }^{14}$ The most common admitting diagnoses in both groups were shock, diabetes and sepsis. Majority of patients were on mechanical ventilation, vasopressor support and nil per os (Table 1).

\begin{tabular}{|c|c|c|c|}
\hline & $\begin{array}{l}\text { Modified Yale } \\
\text { IIP Group } \\
\text { (n=28) }\end{array}$ & $\begin{array}{l}\text { Control } \\
\text { Group } \\
(n=53)\end{array}$ & p-value \\
\hline \multicolumn{4}{|l|}{ Demographics } \\
\hline Age (years, mean $\pm S D)$ & $57.1 \pm 12.6$ & $58.3 \pm 13.7$ & 0.69 \\
\hline Gender & & & 0.50 \\
\hline Male $(n, \%)$ & $11(39.3 \%)$ & $25(47.2 \%)$ & \\
\hline Female (n, \%) & $17(60.7 \%)$ & $28(52.8 \%)$ & \\
\hline $\begin{array}{l}\text { Severity of Illness } \\
\text { (APACHE II, mean } \pm \text { SD) }\end{array}$ & $24.0 \pm 8.4$ & $21.4 \pm 8.7$ & 0.23 \\
\hline \multicolumn{4}{|l|}{ Location $(n, \%)$} \\
\hline MICU & $13(48.1 \%)$ & $20(38.5 \%)$ & 0.41 \\
\hline CENICU & $14(51.9 \%)$ & $32(61.5 \%)$ & \\
\hline \multicolumn{4}{|l|}{ Diagnoses on admission $(n, \%)$} \\
\hline Shock & $21(75.0 \%)$ & $36(67.9 \%)$ & 0.51 \\
\hline Septic & $7(25.0 \%)$ & $10(18.9 \%)$ & 0.52 \\
\hline Cardiogenic & $4(14.3 \%)$ & $12(22.6 \%)$ & 0.37 \\
\hline Hypovolemic & $1(3.6 \%)$ & $2(3.8 \%)$ & 1.00 \\
\hline Multifactorial & $8(28.6 \%)$ & $8(15.1 \%)$ & 0.15 \\
\hline Acute Respiratory Failure & $11(39.3 \%)$ & $12(22.6 \%)$ & 0.11 \\
\hline Sepsis & $20(71.4 \%)$ & $23(43.4 \%)$ & $0.02^{*}$ \\
\hline Acute Coronary Syndrome & $9(32.1 \%)$ & $16(30.2 \%)$ & 0.86 \\
\hline Congestive heart failure & $4(14.3 \%)$ & $9(17.0 \%)$ & 0.75 \\
\hline Arrhythmia & $0(0.0 \%)$ & $6(11.3 \%)$ & 0.09 \\
\hline Post cardiopulmonary arrest & $6(21.4 \%)$ & $6(11.3 \%)$ & 0.22 \\
\hline Cerebrovascular event & $2(7.1 \%)$ & $8(15.1 \%)$ & 0.30 \\
\hline Diabetes & $19(67.9 \%)$ & $19(35.8 \%)$ & $0.01^{*}$ \\
\hline Gastrointestinal bleeding & $10(35.7 \%)$ & $14(26.4 \%)$ & 0.38 \\
\hline Acute Kidney Injury & $8(28.6 \%)$ & $17(32.1 \%)$ & 0.75 \\
\hline Chronic Kidney Disease & $7(25.0 \%)$ & $6(11.3 \%)$ & 0.11 \\
\hline Post-surgical & $5(17.9 \%)$ & $10(18.9 \%)$ & 0.91 \\
\hline CABG & $0(0.0 \%)$ & $3(5.7 \%)$ & 0.55 \\
\hline Neurosurgical & $2(7.1 \%)$ & $4(7.5 \%)$ & 1.00 \\
\hline Others & $3(10.7 \%)$ & $3(5.7 \%)$ & 0.41 \\
\hline \multicolumn{4}{|l|}{ Therapeutic Modalities (n,\%) } \\
\hline Mechanical Ventilation & $22(78.6 \%)$ & $44(83.0 \%)$ & 0.62 \\
\hline Inotropes/vasopressors & $21(75.0 \%)$ & $37(69.8 \%)$ & 0.62 \\
\hline Steroids & $10(35.7 \%)$ & $9(17.0 \%)$ & 0.06 \\
\hline TPN & $5(17.9 \%)$ & $3(5.7 \%)$ & 0.08 \\
\hline NPO & $26(92.9 \%)$ & $53(100 \%)$ & 0.12 \\
\hline $\begin{array}{l}\text { Mean capillary blood glucose } \\
\text { at start of intervention } \\
\text { (mg/dl, mean } \pm \text { s.d.) }\end{array}$ & $243.6 \pm 106.31$ & $245.1 \pm 63.95$ & 0.95 \\
\hline $\begin{array}{l}\text { Duration of the protocol } \\
\text { (hours, mean }+ \text { s.d.) }\end{array}$ & $30.7 \pm 18.4$ & $33.8 \pm 21.2$ & 0.52 \\
\hline
\end{tabular}

\section{Efficacy and Safety Outcomes}

Patients on the Modified Yale IIP achieved a significantly lower mean BG compared with the control group (185.1 vs $212.1 \mathrm{mg} / \mathrm{dl}, \mathrm{p}=<0.05)$ during the entire observation period. However, once normoglycemia was reached, the median BG were already similar for both groups (158.1 vs 159.6 $\mathrm{mg} / \mathrm{dl}, \mathrm{p}=0.14$ ). Time to reach normoglycemia (5 vs 12 hours, $\mathrm{p}<0.05)$ and target BG range of $140-180 \mathrm{mg} / \mathrm{dl}(8.3$ vs 18.3 hours, $\mathrm{p}<0.05$ ) were shorter for the IIP group. There was a significantly higher mean proportion of normal BG in the IIP group. Mean proportion of BG within target range was similar for both groups. A greater number of patients were able to achieve normoglycemia in the IIP group but the proportion of patients who were able to reach target BG was similar. Hypoglycemia was rare for both methods of glycemic control. Table 2 summarizes the efficacy and safety outcomes.

Table 2. Comparison of efficacy and safety outcomes between modified Yale IIP and control group, $\mathrm{N}=81$

\begin{tabular}{|c|c|c|c|}
\hline & $\begin{array}{l}\text { Modified } \\
\text { Yale IIP } \\
(n=28)\end{array}$ & $\begin{array}{l}\text { Control } \\
\text { Group } \\
(n=53)\end{array}$ & p-value \\
\hline \multicolumn{4}{|l|}{ Efficacy Outcomes } \\
\hline \multicolumn{4}{|l|}{ Blood glucose level (mg/dl) } \\
\hline All measurements (mean \pm s.d.) & $185.1 \pm 51.6$ & $212.1 \pm 54.4$ & $0.034^{*}$ \\
\hline $\begin{array}{l}\text { Once normoglycemia achieved } \\
\text { (median) }\end{array}$ & $158.1^{-}$ & $159.6^{-}$ & 0.140 \\
\hline \multicolumn{4}{|l|}{ Time to (hours) } \\
\hline Target $($ mean + s.d.) & $8.3 \pm 9.7$ & $18.3 \pm 11.6$ & $0.001^{*}$ \\
\hline normoglycemia (median) & $5.0^{-}$ & $12.0^{-}$ & $0.001^{*}$ \\
\hline \multicolumn{4}{|c|}{ Mean $\%$ of total measurements in $(\%)$} \\
\hline normoglycemia (mean + s.d.) & $57.4 \pm 29.8$ & $32.9 \pm 28.7$ & $0.001^{*}$ \\
\hline target $($ mean + s.d.) & $21.9 \pm 14.5$ & $17.9+18.5$ & 0.322 \\
\hline \multicolumn{4}{|l|}{ Number of patients (n,\%) } \\
\hline achieved normoglycemia & $28(100.0 \%)$ & $39(73.6 \%)$ & $0.003^{*}$ \\
\hline achieved target range & $24(85.7 \%)$ & $36(67.9 \%)$ & 0.082 \\
\hline \multicolumn{4}{|l|}{ Safety Outcomes } \\
\hline \multicolumn{4}{|l|}{$\%$ of Blood glucose in } \\
\hline hypoglycemia (median) & .0 & .0 & 0.889 \\
\hline severe hypoglycemia (median) & .0 & .0 & 0.310 \\
\hline \multicolumn{4}{|l|}{ Significant difference at $\alpha=0.05$} \\
\hline \multicolumn{4}{|c|}{$\begin{aligned} \text { Normoglycemia : } & 70-180 \mathrm{mg} / \mathrm{dl} \text {; target : } 140-180 \mathrm{mg} / \mathrm{dl} \text {; off-target : } \\
& <70,>180 \mathrm{mg} / \mathrm{dl}\end{aligned}$} \\
\hline
\end{tabular}

\section{Clinical Outcomes}

Four patients in the IIP group were excluded from the analysis for clinical outcomes due to submaximal treatment. One patient had advanced directives orders ("Do not resuscitate") and 3 went home against medical advice. There were no significant differences noted in allcause mortality, cardiovascular mortality and occurrence of any morbidity between the two groups. Among the specific complications, only the need for transfusion of packed red cells was seen to be significantly higher in the IIP group. The IIP group had a significantly longer ICU and hospital stay (Table 3).

\section{Protocol Deviations}

All charts (28) which employed the Modified Yale IIP were examined for protocol deviations. Of the 518 capillary BG determinations, 296 episodes (57.1\%) of deviations were identified. Majority (66.9\%) were errors on insulin dose administered (Table 4). Majority of patients had deviations in more than one category with $35.7 \%$ in all three, $46.4 \%$ in two and $17.9 \%$ in one category. All patients had at least one deviation. On a per patient basis, a mean of 11 episodes of deviations occurred. Four patients had more than $50 \%$ deviations in at least one category. Subgroup analysis of patients with acceptable protocol deviations $(<50 \%)$ yielded slight improvement in the efficacy parameters. Comparison with the control group yielded identical comparisons of efficacy and safety (Table 5). 


\begin{tabular}{|c|c|c|c|}
\hline & $\begin{array}{l}\text { Modified Yale } \\
\text { IIP Group } \\
(n=24)\end{array}$ & $\begin{array}{c}\text { Control Group } \\
(n=53)\end{array}$ & $\mathrm{p}$-value \\
\hline All cause Mortality $(n, \%)$ & $15(62.5 \%)$ & $36(69.2 \%)$ & 0.56 \\
\hline Cardiovascular mortality (n, \%) & $5(20.8 \%)$ & $14(27.5 \%)$ & 0.54 \\
\hline Morbidity $(\mathrm{n}, \%)$ & $17(70.8 \%)$ & $32(61.5 \%)$ & 0.43 \\
\hline CP arrest, revived & $4(16.7 \%)$ & $5(9.4 \%)$ & 0.36 \\
\hline New cardiovascular event & $2(8.3 \%)$ & $2(3.8 \%)$ & 0.59 \\
\hline Initiation of mechanical ventilation & $1(4.2 \%)$ & $4(7.5 \%)$ & 1.00 \\
\hline Initiation of vasopressors/ inotropic support & $4(16.7 \%)$ & $16(30.2 \%)$ & 0.21 \\
\hline Addition of vasopressors & $8(33.3 \%)$ & $9(17.0 \%)$ & 0.11 \\
\hline New infection & $8(33.3 \%)$ & $12(22.6 \%)$ & 0.32 \\
\hline New Renal dysfunction & $2(8.3 \%)$ & $3(5.7 \%)$ & 0.64 \\
\hline Need for transfusion of packed RBC & $10(41.7 \%)$ & $11(20.8 \%)$ & 0.05 \\
\hline Arrhythmia & $2(8.7 \%)$ & $4(7.5 \%)$ & 1.00 \\
\hline ICU stay (days, median) & 5.5 & 3.0 & $0.01^{*}$ \\
\hline Hospital stay (days, median) & 13.9 & 8.1 & $0.02^{*}$ \\
\hline
\end{tabular}

Table 4. Summary of protocol deviations with the use of the modified Yale IIP

\begin{tabular}{lccc}
\hline Category of deviation & $\begin{array}{c}\text { Proportion from } \\
\text { total deviations } \\
\mathbf{n}=\mathbf{2 9 6}\end{array}$ & $\begin{array}{c}\text { Episodes per } \\
\text { patient } \\
\text { (mean, range) }\end{array}$ & $\begin{array}{c}\text { Mean proportion per patient } \\
\text { (episodes/total CBGs per } \\
\text { patient) }\end{array}$ \\
\hline Timing of CBG determination & $24 \%$ & $2.53(0,16)$ & $12.9 \%$ \\
Insulin dose administered & $66.9 \%$ & $7.07(1,24)$ & $30.7 \%$ \\
Hypoglycemia protocol & $9.1 \%$ & $0.96(0,5)$ & $32.1 \%{ }^{*}$ \\
\hline - $\quad$ (number of deviations/number of episodes with need for hypoglycemia protocol per patient) $\times 100$
\end{tabular}

Table 5. Comparison of efficacy and safety outcomes between all patients in the modified Yale IIP, those with acceptable protocol deviations (PD) and with the contro group

\begin{tabular}{|c|c|c|c|}
\hline \multirow[b]{2}{*}{ Efficacy Outcomes } & \multicolumn{2}{|c|}{ Modified Yale IIP Group } & \multirow{2}{*}{$\begin{array}{c}\text { Modified Yale IIP with } \\
\text { Acceptable PD* vs } \\
\text { Control group }\end{array}$} \\
\hline & $\begin{array}{c}\text { All } \\
(n=28)\end{array}$ & $\begin{array}{c}\text { Acceptable PD* } \\
(n=24)\end{array}$ & \\
\hline \multicolumn{4}{|l|}{ Blood glucose level (mg/dl) } \\
\hline All measurements (mean \pm s.d.) & $185.1 \pm 51.6$ & $182.0 \pm 49.2$ & .023 \\
\hline Once normoglycemia achieved (median) & $158.1^{-}$ & $153.1^{-}$ & .087 \\
\hline \multicolumn{4}{|l|}{ Time to (hours) } \\
\hline Target $($ mean + s.d.) & $8.3 \pm 9.7$ & $8.3 \pm 9.7$ & .001 \\
\hline normoglycemia (median) & $5.0^{-}$ & $4.5^{-}$ & .000 \\
\hline \multicolumn{4}{|l|}{$\%$ of total measurements $(\%)$} \\
\hline normoglycemia (mean + s.d.) & $57.4 \pm 29.8$ & $59.8 \pm 28.3$ & .000 \\
\hline target $($ mean + s.d. $)$ & $21.9 \pm 14.5$ & $23.5 \pm 14.8$ & .202 \\
\hline \multicolumn{4}{|l|}{ Number of patients $(n, \%)$} \\
\hline achieved normoglycemia & $28(100 \%)$ & $24(100.0 \%)$ & .005 \\
\hline achieved target range & $24(85.7 \%)$ & $21(87.5 \%)$ & .070 \\
\hline \multicolumn{4}{|l|}{ Safety Outcomes } \\
\hline$\%$ of Blood glucose in & & & \\
\hline hypoglycemia (median) & 0 & .0 & 0.928 \\
\hline severe hypoglycemia (median) & 0 & .0 & 0.348 \\
\hline
\end{tabular}

\section{DISCUSSION}

In our institution, glycemic management of the critically ill is not standardized. The majority of physicians still use sliding scale subcutaneous insulin. In 2009, the Modified Yale IIP was introduced in an effort to improve patient care and adhere to current recommendations on ICU glycemic management. Our study aimed to evaluate the IIP as it is being implemented in actual practice.

Our study was able to show that use of the Modified Yale IIP is efficaceous and safe. The IIP is efficaceous because the majority of patients were able to reach acceptable glucose levels in a reasonable time. Normoglycemia and target ranges were achieved at 5 and 8.4 hours respectively. The majority $(58.3 \%)$ of BGs were within normoglycemic range. Once normoglycemia was achieved, the mean BG was $155.2 \mathrm{mg} / \mathrm{dl}$ The IIP is safe because hypoglycemia was rare with a median of zero events.

Compared to other methods, the Modified Yale IIP resulted in more favorable efficacy outcomes. More patients achieved normoglycemic glucose range. A lower mean BG was reached. Target and normoglycemic levels were reached faster. Outcomes were in favor of the IIP despite a higher proportion of diabetes and sepsis, factors known to perpetuate hyperglycemia, in the IIP group. 
However, proportion of BG achieving target range was similar. These results are comparable with the initial evaluation done by Josol, et al., in 2009. In this study, the Modified Yale IIP was employed in 50 ICU patients and compared with 50 patients managed differently. Similar to our review, the IIP demonstrated shorter median time to normoglycemia at 4 hours versus 12 hours for control group. The IIP group also had a higher proportion of BG in the normoglycemic range at $73.8 \%$ compared to $51.7 \%$ for the control group. Hypoglycemia was minimal at $0.6 \%$ for the IIP group. ${ }^{11}$

There are some differences noted between the two studies. In the study of Josol, the mean BG was $161 \mathrm{mg} / \mathrm{dl}$ for the IIP group. This is lower than what we achieved which is at $185.1 \mathrm{mg} / \mathrm{dl}$. Furthermore, the first study achieved a higher proportion of BG in the normoglycemic $(73.8 \%)$ and target $(30 \%)$ ranges. One possible reason for the disparity could be the differences in the characteristics of the two cohorts. Our patients had more severe illness as shown by a higher mean Apache II score, more patients on ventilatory and vasopressor support, with diabetes and on steroids. These factors may make glycemic control more difficult. A second reason may be the settings of the study. Unlike the past review which is in ideal set-up, our current study is a "real-world" setting with confounding factors like logistics and proficiency of implementing staff influencing outcomes.

The Yale IIP was also employed and modified in other centers. $^{15-18}$ In the study of Tamaki, et al., conducted in Japan, a cohort of 40 cardiac surgery patients were compared to a historical cohort of 35 patients. A significantly higher proportion of target BG (78\% vs 57\%) was demonstrated in the IIP group. Time to target was also shorter for the IIP group (3.1 vs 5.0 hours). ${ }^{15}$ These favorable results were likewise reported in centers in Brazil, Portugal and the US. ${ }^{16-18}$

In our study, a substantial number of protocol deviations occurred. The most frequent deviation was on improper insulin dose adjustment followed by improper timing of BG checks. Despite the prevalence of protocol deviations, the III group still resulted in better glycemic outcomes. In a survey on the experience of our medical staff on the use of the Modified Yale IIP, our nurses noted that the most difficult and error-prone tasks were initiating the insulin drip followed by adjusting the insulin drip rate. The nurses explained that the multistep instruction of the protocol can be confusing and time-consuming. ${ }^{19}$ Simplicity and clarity are, therefore, desirable attributes of a protocol. ${ }^{20}$ The attitude and skill of the implementing staff also likely affect the occurrence of protocol deviations. Clear understanding of the IIP's promised benefits will lead to an improved attitude despite the increase in workload. ${ }^{21}$ It is of utmost importance to improve the skill of implementing hospital staff to preserve the integrity of the protocol and derive the best benefit. Frequent and periodic training, streamlining and feedback should be done.

Suboptimal compliance to the IIP has been similarly reported. In the study of Malasker, et al., 75\% of all BG measurements were associated with protocol deviations. Majority (57\%) of deviations were improper timing of BG checks followed by $38 \%$ on erroneous insulin dose adjustment. ${ }^{22} \quad$ A similar situation was seen in Brigham and Women's Hospital as reported by Cyrus et al., where $31.2 \%$ of insulin adjustments were incorrect and $55.2 \%$ of glucose checks were done beyond 10 minutes of the prescribed time. ${ }^{23}$

Comparison of mortality and morbidity showed little differences in our study apart from an increase in blood transfusion in the III group. These results are consistent with the report of Josol. ${ }^{11}$ A similar study by Krinsley which compared glycemic and clinical outcomes before and after institution of an ICU glucose management protocol reported otherwise. In this study of 1600 patients, the use of an IIP resulted in a $29.3 \%$ decrease in mortality, $75 \%$ decrease in new renal insufficiency and $18.7 \%$ decrease in blood transfusion. Perhaps, the disparity is due to the small number of patients in whom the IIP was used in our study, such that we did not achieve statistical power to detect the difference. Another reason could be the differences in BG achieved. In our study, the mean BG after use of the Modified Yale IIP was $182.3 \mathrm{mg} / \mathrm{dl}$ which is higher than that achieved by the group of Krinsley at $130.7 \mathrm{mg} / \mathrm{dl} .{ }^{24}$

It is difficult to determine why patients in the IIP group in our study had a longer ICU and hospital day stay. This is in contrast to the results of Krinsley which showed a $10.8 \%$ decrease in length of hospital stay. ${ }^{24}$ One possible explanation may be the higher proportion of sepsis in the IIP group. Presence of sepsis and infection in the $1^{\text {st }} 24$ hours in the ICU has been shown to be associated with longer ICU and hospital stay. ${ }^{25,26}$

Our study has several limitations. First, it is a retrospective study which assumes that the two groups compared are similar. The two groups are reasonably comparable, the majority of the demographic characteristics are statistically similar. Two variables, the percentage of patients with sepsis and diabetes, were cause for heterogeneity. However, despite a higher proportion of these factors, glycemic outcomes were still better in the IIP group. Since the IIP was used at the discretion of physicians, level of care and conscientiousness in achieving glycemic targets by the medical staff may confound the comparison of outcomes between the IIP and control groups. However, we can still attribute benefit to the IIP because, even without comparing it to the control group, it yielded good outcomes. Other variables which may affect outcomes such as hospital policies, nursing staff or logistics were 
assumed to be similar since the observation period is the same.

Secondly, occurrence of hypoglycemia was based solely on BG entries in monitoring sheets and notes. Episodes of hypoglycemia may have been unrecognized by patients or failed to have been recorded by health care providers leading to underreporting of these events.

Thirdly, measurement of BG was via capillary blood glucose. In light of the high proportion of patients in shock, these values may not be entirely accurate since disparity can occur with peripheral vasoconstriction and endothelial dysfunction. Capillary blood glucose, however, is more practical and is the method used in usual clinical practice. Measurement of arterial BG will entail either an indwelling catheter or frequent phlebotomy which is not usual in our set-up. Furthermore, the glucose meters were the standard machines used in the ICUs at the time of observation but we cannot ascertain if these were changed during the two years of observation. Lastly, as was previously stated, this study was not statistically powered to detect a difference in clinical outcomes such as mortality and morbidity.

We have several recommendations based on the results of this study. First, improve the process of implementing the Modified Yale IIP by wider dissemination of its relevance, periodic training of the ICU staff on carrying out the protocol, provide avenues for consultation and streamlining of the protocol and secure institutional support. We also recommend further investigations on the efficacy, safety and effect on duration of ICU and hospital stay of the Modified Yale IIP through prospective studies and, perhaps, compare it with other standardized protocols.

\section{CONCLUSION}

The Modified Yale IIP is efficaceous and safe for ICU patients. Compared with other methods of glycemic control, use of the protocol yielded better glycemic profiles. A significant amount of protocol deviations occurred, with the most common being errors in insulin dose adjustment.

\section{References}

1. Capes SE, Hunt D, Malmberg K, Gerstein HC. Stress hyperglycaemia and increased risk of death after myocardial infarction in patients with and without diabetes: A systematic overview. Lancet. 2000;355:773-778.

2. Cheung NW, Wong VW, McLean M. The Hyperglycemia: Intensive Insulin Infusion in Infarction (HI-5) study: A randomized controlled trial of insulin infusion therapy for myocardial infarction. Diabetes Care. 2006;29:765-770.
3. Svensson AM, McGuire DK, Abrahamsson P, Dellborg M. Association between hyper- and hypoglycaemia and 2 year all-cause mortality risk in diabetic patients with acute coronary events. Eur Heart J. 2005;26:12551261.

4. Kosiborod M, Rathore SS, Inzucchi SE, et al. Admission glucose and mortality in elderly patients hospitalized with acute myocardial infarction: Implications for patients with and without recognized diabetes. Circulation. 2005;111:3078-3086.

5. Fogelholm R, Murros K., Rissanen A, Avikainen S. Admission blood glucose and short term survival in primary intracerebral haemorrhage: A population based study. J Neurol Neurosurg Psychiatry 2005;76:349-353.

6. Ata A, Lee J, Bestle SL, Desemone J, Stain SC. Postoperative hyperglycemia and surgical site infection in general surgery patients. Arch Surg. 2010;145(9):858-864.

7. Yendamuri S, Fulda GF, Tinkoff GH. Admission hyperglycemia as a prognostic indicator in trauma. J Trauma. 2003;55:33-38

8. Furnary AP, Wu Y, Bookin SO. Effect of hyperglycemia and continuous intravenous insulin infusions on outcomes of cardiac surgical procedures: The Portland Diabetic Project. Endocr Pract. 2004;10(suppl 2):21-33.

9. American Diabetes Association. Standards of Medical Care in Diabetes2011. American Diabetes Association Position Statement. Diabetes Care. January 2011;34(Supp 1):S11-S16.

10. Goldberg PA, Siegel MD, Sherwin RS, et al. Implementation of a safe and effective insulin infusion protocol in a medical intensive care unit. Diabetes Care. 2004;27:461-467.

11. Josol CV, Cardino MJ, Jimeno CA, Isip-Tan IT. Efficacy and safety of the UP-PGH endocrine insulin infusion protocol in controlling hyperglycemia in UP-PGH Medical Intensive Care Unit and Central Intensive Care Unit. 2006 (unpublished).

12. Department of Medicine, University of the Philippines-Philippine General Hospital Medical Intensive Care Unit Annual Census. 2010 (unpublished).

13. Department of Medicine, University of the Philippines-Philippine Genera Hospital Central Intensive Care Unit Annual Census. 2010 (unpublished).

14. Chiavone PA, Sens YA. Evaluation of APACHE II System among Intensive Care patients at a teaching hospital. Sao Paulo Me J. 2003 Mar 5; 121 (2):53-7.

15. Tamaki M, Shimizu T, Kanazawa A, et al. Efficacy and safety of modified Yale insulin infusion protocol in Japanese diabetic patients after open-heart surgery. Diabetes Res Clin Pract. 2008 Sep;81(3):296-302.

16. Oliveira S. Yale insulin protocol infusion in sepsis patients. Critical Care 2011;15(Suppl 3):P5.

17. Bolton M, Richard A, Blonde L, Burshell A. Effective glycemic management in hospitalized patients: A multidisciplinary approach. Ochsner J. 2007; 7(2):52-7.

18. Diener JRC, Dos Prazeres CEE, D Rosa CM, Alberton UC, Ramos CCS. Assessment of effectiveness and safety of Yale insulin infusion protocol in a Brazilian Medical and Surgical Intensive Care Unit. Revista Brasileira de Terapia Intensiva. 2006;18(3):268-275.

19. Ngalob QG, Jimeno CA, Isip-Tan IT., Medical staff experience of an ICU insulin infusion protocol in a tertiary hospital in the Philippines. 2012 (unpublished).

20. Sauer P, Van Horn ER. Impact of intravenous insulin protocols on hypoglycemia, patient safety, and nursing workload. Dimensions of Critical Care Nursing. 2009; 28(3): 95-101.

21. Goldberg PA, Inzucchi SE. Selling root canals: Lessons learned from implementing a hospital insulin infusion protocol. Diab Spectr. 2005 January; 18(1):28-33.

22. Malesker MA, Foral PA, McPhillips AC, Christensen KJ, Chang JA, Hilleman DE. An efficiency evaluation of protocols for tight glycemic control in Intensive Care Units. Am J Crit Care. 2007;16:589-598

23. Cyrus RM, Szumita PM, Greenwood BC, Pendergrass ML. Evaluation of compliance with a paper-based, multiplication-factor, intravenous insulin protocol. Ann Pharmacother. 2009 Sep;43(9):1413-8.

24. Krinsley JS. Effect of an intensive glucose management protocol on the mortality of critically ill adult patients. Mayo Clin Proc. 2004 Aug;79(8):992-1000.

25. Arabi Y, Venkatesh S, Haddad S, Shimemeri AA, Malik SA. A prospective study of prolonged stay in the intensive care unit: Predictors and impact on resource utilization. Int J Qual Health Care.2002; 14 (5):403-410.

26. Vincent JL, Sakr Y, Sprung CL, et al. Sepsis in European Intensive Care Units: Results of the SOAP study. Crit Care Med. 2006; 34:344-353.

Articles and any other material published in the JAFES represent the work of the author(s) and should not be construed to reflect the opinions of the Editors or the Publisher. Authors are required to accomplish, sign and submit scanned copies of the JAFES Declaration: that the article represents original material, that is not being considered for publication or has not been published or accepted for publication elsewhere. Consent forms, as appropriate, have been secured for the publication of information about patients; otherwise, authors declared that all means have been exhausted for securing such consent. The authors have signed disclosures that there are no financial or other relationships that might lead to a conflict of interest. All authors are required to submit Authorship Certifications that the manuscript has been read and approved by all authors, and that the requirements for authorship have been met by each author. 


\section{APPENDIX. MODIFIED YALE INSULIN INFUSION PROTOCOL (IIP)}

\section{INITIATING AN INSULIN INFUSION}

1. INSULIN INFUSION: Mix 1 unit Human Regular Insulin per $1 \mathrm{cc} 0.9 \% \mathrm{NaCl}$. Administer in infusion pump (in increments of 1 unit/h).

2. PRIMING: Flush 50cc of infusion through all IV tubing before infusion begins (to saturate the insulin binding sites in the tubing).

3. THRESHOLD: Start IV insulin if BG is $>\mathbf{1 8 0} \mathbf{~ m g} / \mathbf{d l}$.

4. TARGET BLOOD GLUCOSE LEVELS: $\mathbf{1 4 0 - 1 8 0 ~} \mathbf{~ m g / d L}$

5. BOLUS \& INITIAL INSULIN INFUSION RATE: If initial BG $>180 \mathrm{mg} / \mathrm{dl}$ but $<300 \mathrm{mg} / \mathrm{dl}$, divide by 100 , then round to the nearest 1 unit for initial drip rate, (don't give IV bolus insulin). If initial BG is $\geq 300 \mathrm{mg} / \mathrm{dl}$, divide by 100 for bolus and initial drip rate.

\section{BLOOD GLUCOSE MONITORING}

1. Check blood glucose hourly until stable (3 consecutive values within target range). In hypotensive patients, capillary blood glucose (i.e., fingersticks) may be inaccurate and obtaining blood sample from an indwelling vascular catheter may be preferable.

2. Then check blood glucose q 2 hours; once stable x 12-24 hrs. Blood glucose checks can then be spaced to q 4 hrs. IF:

a. no significant change in clinical condition AND

b. no significant change in nutritional intake

3. If any of the following occur, consider the temporary resumption of hourly blood glucose monitoring, until blood glucose is again stable (2-3 consecutive BG values within target range):

a. any change in insulin infusion rate (i.e. blood glucose out of target range)

b. significant changes in clinical condition

c. initiation or cessation of pressor or steroid therapy

d. initiation or cessation of renal replacement therapy (dialysis, CVVH, etc.)

e. initiation, cessation, or rate change of nutritional support (TPN, PPN, tube feedings, etc.)

\section{CHANGING THE INSULIN INFUSION RATE}

\section{If $\mathrm{BG}<50 \mathrm{mg} / \mathrm{dL}$ :}

\section{D/C INSULIN INFUSION:}

Give 1 amp (25 g) D50 IV; recheck blood glucose q 15 minutes.

- When blood glucose $\geq 100 \mathrm{mg} / \mathrm{dL}$, wait 1 hour, recheck BG. If still $\geq 100 \mathrm{mg} / \mathrm{dL}$, restart infusion at $50 \%$ of most recent rate.

\section{If BG 50-69 mg/dL:}

\section{D/C INSULIN INFUSION:}

If symptomatic (or unable to assess), give $1 \mathrm{amp}(25 \mathrm{~g}) \mathrm{D} 50 \mathrm{IV}$; recheck blood glucose q 15 mins.

If asymptomatic, give $1 / 2$ amp (12.5 g) D50 IV; recheck BG q 30 mins.

- When $B G \geq 100 \mathrm{mg} / \mathrm{dl}$, wait 1 hour, recheck BG. If still $\geq 100 \mathrm{mg} / \mathrm{dl}$, restart infusion at $75 \%$ of most recent rate (round off to the nearest 1 unit)

\section{If BG 70-99 mg/dl:}

\section{D/C INSULIN INFUSION FOR 30 mins.}

If repeat $C B G \geq 100 \mathrm{mg} / \mathrm{dl}$, restart insulin infusion at $75 \%$ of most recent rate (round off to the nearest 1 unit)

If repeat CBG is still $<100 \mathrm{mg} / \mathrm{dl}$, re-chek CBG after 1 hour., resume insulin infusion only at $75 \%$ of most recent rate once repeat $\mathrm{CBG}$ is $\geq 100 \mathrm{mg} / \mathrm{dl}$ (round off to the nearest 1 unit)

If $B G \geq 100$

STEP 1: Determine CURRENT BG \& identify column in table

\begin{tabular}{|l|l|l|l|}
\hline BG 100-139 mg/dl & BG 140-179 $\mathrm{mg} / \mathrm{dl}$ & BG 180-249 $\mathrm{mg} / \mathrm{dl}$ & BG $\geq 250 \mathrm{mg} / \mathrm{dl}$ \\
\hline
\end{tabular}


STEP 2: Determine the RATE OF CHANGE from prior BG level- identifies a CELL in the table- Then move right for the INSTRUCTIONS:

(Note: If the last BG was measured 2-4 hrs. before the current BG, calculate the hourly rate of change.)

\begin{tabular}{|c|c|c|c|c|}
\hline BG 100-139 mg/dl & BG 140-179 mg/dl & BG 180-249 mg/dl & $B G \geq 250 \mathrm{mg} / \mathrm{dl}$ & Instructions \\
\hline & & $\mathrm{BG} \uparrow$ by $>40 \mathrm{mg} / \mathrm{dl} / \mathrm{hr}$ & $\mathrm{BG} \uparrow$ & $\uparrow$ Infusion by " $2 \Delta$ " \\
\hline & $\mathrm{BG} \uparrow$ by $>20 \mathrm{mg} / \mathrm{dl} / \mathrm{h}$ & $\begin{array}{l}\mathrm{BG} \uparrow \text { by } 1-40 \mathrm{mg} / \mathrm{dl} / \mathrm{h} \\
\text { or BG unchanged }\end{array}$ & $\begin{array}{l}\text { BG unchanged } \\
\text { or BG } \downarrow \text { by } 1-40 \\
\mathrm{mg} / \mathrm{dl} / \mathrm{h}\end{array}$ & $\uparrow$ Infusion by " $\Delta$ " \\
\hline $\mathrm{BG} \uparrow$ & $\begin{array}{l}\text { BG } \uparrow \text { by } 1-20 \\
\mathrm{mg} / \mathrm{dl} / \mathrm{h}, \mathrm{BG} \\
\text { UNCHANGED, } \\
\text { OR BG } \downarrow 1-20 \\
\mathrm{mg} / \mathrm{dl} / \mathrm{h}\end{array}$ & BG $\downarrow$ by $1-40 \mathrm{mg} / \mathrm{dl} / \mathrm{h}$ & $\begin{array}{l}\text { BG } \downarrow \text { by } 41-80 \\
\mathrm{mg} / \mathrm{dl} / \mathrm{h}\end{array}$ & No infusion change \\
\hline $\begin{array}{l}\text { BG UNCHANGED } \\
\text { OR BG } \downarrow \text { by } \\
1-20 \mathrm{mg} / \mathrm{dl} / \mathrm{h}\end{array}$ & $\begin{array}{l}\text { BG } \downarrow \text { by } 21-40 \\
\mathrm{mg} / \mathrm{dl} / \mathrm{h}\end{array}$ & $\mathrm{BG} \downarrow$ by $41-80 \mathrm{mg} / \mathrm{dl} / \mathrm{h}$ & $\begin{array}{l}\text { BG } \downarrow \text { by } 81-120 \\
\mathrm{mg} / \mathrm{dl} / \mathrm{h}\end{array}$ & $\nabla$ Infusion by “ $\Delta$ " \\
\hline $\begin{array}{l}\text { BG } \downarrow \text { by } \\
>20 \mathrm{mg} / \mathrm{dl} / \mathrm{h} \\
\text { *see below }\end{array}$ & BG $\downarrow$ by $>40 \mathrm{mg} / \mathrm{dl} / \mathrm{h}$ & $\mathrm{BG} \downarrow$ by $>80 \mathrm{mg} / \mathrm{dl} / \mathrm{h}$ & $\begin{array}{l}\text { BG } \downarrow \text { by }>120 \\
\mathrm{mg} / \mathrm{dl} / \mathrm{h}\end{array}$ & $\begin{array}{l}\text { Hold X } 30 \text { mins., } \\
\text { then } \\
\downarrow \text { Infusion by " } 2 \Delta \text { " }\end{array}$ \\
\hline
\end{tabular}

${ }^{*}$ D/C INSULIN INFUSION, check CBG after 30 mins., when BG is $\geq 100 \mathrm{mg} / \mathrm{dl}$, restart infusion at $75 \%$ of most recent rate

CHANGES IN INFUSION RATE (" $\Delta$ ") are determined by the current rate:

\begin{tabular}{|l|l|l|}
\hline $\begin{array}{l}\text { Current Rate } \\
\text { (units/hr) }\end{array}$ & $\Delta=$ rate change (units/hr) & $\begin{array}{l}2 \Delta=2 \times \text { rate change } \\
\text { (units/hr) }\end{array}$ \\
\hline$<3$ & 0.5 & 1 \\
\hline $3-6$ & 1 & 2 \\
\hline $6.5-9.5$ & 1.5 & 3 \\
\hline $10-14.5$ & 2 & 4 \\
\hline $15-19.5$ & 3 & 6 \\
\hline $20-24.5$ & 4 & 8 \\
\hline$\geq 25$ & $\geq 5$ & 10 (consult MD) \\
\hline
\end{tabular}

